\title{
EDITORIAL
}

\section{AUSTERIDAD, INEQUIDAD Y DESIGUALDAD}

La batalla contra la desigualdad y la lucha por la equidad no se logra con las políticas de austeridad. Todo lo contrario. La eliminación de la desigualdad y la inequidad de los ingresos son un reto para las políticas relacionadas con el desarrollo económico en sociedades democráticas. Por ello, dichos temas han tomado fuerza en muchos autores que intentan mostrar cómo la concentración del ingreso ha dañado durante las últimas décadas a la clase media de los países de América Latina, Europa, Estados Unidos y otros desarrollados. Incluso, muchos países latinoamericanos fueron el laboratorio de políticas de austeridad para enfrentar las crisis económicas y financieras durante los años ochenta y noventa, profundizando la inequidad y la desigualdad. El efecto de dichas políticas propició una alternativa democrática contraria a la imperante años atrás, principalmente en los países de América del Sur. Los cambios de gobierno con inclusión social hicieron que mejoraran los indicadores de pobreza a raíz de políticas económicas que revirtieron las de austeridad. Por supuesto, el alto precio de los commodities en los mercados financieros internacionales y mayores retenciones para los gobiernos hicieron posible mejorar el índice de desarrollo humano.

Las teorías del desarrollo contemporáneas parten de la relación de la $\mathrm{U}$ invertida entre el ingreso nacional y la desigualdad económica de Kuznets para analizar la distribución del ingreso. Estudio realizado a partir del proceso de industrialización y el crecimiento económico en Estados Unidos que se puede generalizar a sociedades desarrolladas. Por ello, la industrialización para muchos autores, Prebisch para América Latina, fue la hipótesis que sostuvo la "sustitución de importaciones" como la etapa necesaria para lograr el desarrollo económico acompañado de un Estado de bienestar redistributivo. La industrialización vendría a ser la plataforma necesaria para ampliar una clase media con mejores ingresos. Al pasar de sociedades rurales a una industrial y urbana, la demanda de empleos mejor remunerados acrecentaría, sin lugar a dudas, la riqueza de la sociedad. La preocupación por la igualdad y una mejor distribución del ingreso de Thomas Piketty en su libro El capital en el siglo XXI. Se concentra en señalar como “...cuando la tasa de rendimiento del capital supera de modo constante la tasa de crecimiento de la producción y del ingreso, el capitalismo produce mecánicamente desigualdades insostenibles, arbitrarias, que cuestionan de modo radical los valores 
meritocráticos en los que se fundamentan nuestras sociedades democráticas”. Pero más allá de ello coincide en que la desigualdad es materia de política económica.

La propuesta de la Comisión Económica para América Latina y el Caribe (Cepal) vertida en el Panorama económico y social de América Latina se sintetiza en la "trilogía de la igualdad" que recientemente presentó la secretaria ejecutiva Alicia Bárcena al recibir la Cátedra Maestro Ricardo Torres Gaitán en el Instituto de Investigaciones Económicas de la unAM. "La igualdad es el horizonte, el cambio estructural con empleo, el camino y, la política el instrumento". Las dimensiones de la desigualdad se centran en "...la educación, el acceso a las tecnologías de la información y las comunicaciones, el hacinamiento y la falta de acceso a los bienes duraderos, la segregación residencial en las ciudades asociado a los bienes de consumo privado y a la ausencia de bienes públicos". Por tanto, con políticas de austeridad es imposible lograr la igualdad y terminar con las condiciones de vulnerabilidad. Son las políticas públicas la materia necesaria para revertir la situación actual de desigualdad, inequidad y austeridad.

James Galbraith ha señalado que a partir de las políticas de austeridad la desigualdad empezó a crecer en la segunda mitad de los años ochenta. Todo lo contrario a la teoría neoclásica; la cual parte de los supuestos de que mediante los mercados competitivos, el cambio tecnológico y la globalización del comercio se propiciaría la disminución de las desigualdades al interior de los países. Incluso se fue diferenciando a los trabajadores calificados de los no calificados. Más allá de estos planteamientos, la visión neoclásica, no relaciona la desigualdad con el desempleo y el tipo de cambio. Lo cierto es que la "gobernabilidad financiera mundial" acompañada del ajuste en las tasas de interés globales y su relación con la crisis de deuda y, posteriormente, la deflación de la deuda, incidieron en la desigualdad al orientar las políticas monetarias, fiscales y financieras a pagar el servicio de la deuda a favor de los inversionistas e instituciones reduciendo el gasto público. Por tanto, un auge del crédito y ganancias extraordinarias en la esfera financiera durante el periodo de la Gran Moderación propiciaron la Gran Crisis a partir de 2008.

Las últimas cuatro décadas profundizaron cambios estructurales desdibujando el Estado de bienestar redistributivo y la importancia del banco central como empleador de última instancia. Hoy las sociedades democráticas se juegan su destino ante la caída del precio de los commodities, la creciente deuda soberana y el continuo discurso de la austeridad. Lo más complicado en este momento para la civilización es resolver el creciente desempleo que oscurece el desarrollo y revertir que $1 \%$ de la población representa $50 \%$ del 
ingreso total en escala mundial. Al día de hoy, la Gran Recesión caracterizada por el estancamiento económico, la caída de los precios a nivel internacional y la deflación requiere de políticas económicas canalizadas a proyectos de infraestructura de envergadura que ofrezcan una espiral ascendente del empleo, acompańadas del crédito de una banca de desarrollo pública. Seguir con la austeridad es profundizar la pobreza, el desempleo y, en consecuencia, minar la democracia.

Un fenómeno económico de extrema importancia es el debate sobre la fuga de capitales internacionales y su efecto en la estabilidad y el desarrollo de las economías en el contexto de la globalización financiera. Cómo definir ese fenómeno y, principalmente, cómo medirlo es el núcleo del trabajo "Fuga de capitales en México: análisis y propuesta de medición”, de Andrés Blancas. Además de evidenciar los hechos estilizados que históricamente amarran la volatilidad de los capitales extranjeros a las recurrentes crisis financieras, el artículo es imprescindible tanto por criticar las formas tradicionales para medir la fuga de capitales, como por presentar una novedosa metodología para estimar, con base en la contabilidad social, el monto de recursos que salieron de México durante la creciente desestabilización económica y financiera que sufrió el país entre 1980 y 1998. La discusión ofrecida por el autor gana renovada importancia en el marco de la Gran Recesión que da la tónica del desempeño de la economía mundial tras la crisis financiera de 2008. La instrumentación adecuada para el análisis empírico deja en descubierto la ingente fragilidad financiera que todavía impera en la arquitectura de las finanzas estructuradas. Seguir depurando el instrumental analítico disponible representado en la metodología sugerida por el autor es una aportación a atender en la medición de los movimientos de los flujos de capital ante la inestabilidad de los países. Acercarse más precisamente al volumen que está sujeto a evadirse del país en la forma masiva fuga de capitales de corto plazo es parte fundamental del trabajo académico para contribuir en las discusión de políticas públicas y de regulación del mercado.

Violeta Rodríguez en su artículo "Límites de la estabilidad cambiaria de México" se concentra en el análisis de la estabilidad del tipo de cambio, y cómo éste afecta a las variables reales en un proceso de financiarización. Plantea la hipótesis de que la coordinación de la política monetaria y cambiaria conforma la estrategia de intervención esterilizada, misma que, aplicada a México, no tuvo siempre la misma disponibilidad de recursos para ser financiada de manera autónoma, lo que llevó a tener fuertes desbalances en la administración de reservas internacionales. El proceso de intervención esterilizada es un factor que garantiza el monto y la capacidad de pagar una ganancia, princi- 
palmente a grandes inversionistas internacionales. Ante ello, México se vio obligado a incorporar la política de esterilización en el mercado cambiario, y conjuntamente con la política monetaria se logra controlar la inflación, la tasa de interés y el tipo de cambio, ubicándolas como políticas que garantizan el valor de los activos financieros y los pasivos del sector no financiero, lo que la autora llama: las intervenciones esterilizadas con una política financiarizadora. Ante el escenario de inestabilidad en las variables externas, la estrategia de intervenciones esterilizadas es un tema central, por lo cual se plantea un modelo para evidenciar los límites que se tiene cuando se alcanza cierta estabilidad. Así, se plantea un modelo de simulación segmentado de ecuaciones en diferencias con coeficientes variables, con la finalidad de observar las estabilidad de las variables en cuestión; para su análisis se hace el estudio partiendo de una segmentación temporal, es decir, se analizó en cuatro diferentes etapas históricas. El camino y la aplicación de estrategias de intervención esterilizadas converge a un modelo que tiene cada vez más componentes estabilizadores, ello quiere decir, que el tipo de cambio, deuda externa y reservas internacionales incorporaran elementos de estabilidad, factores exógenos como los choques petroleros y la prima de riesgo hacen vulnerable al modelo planteado; lo que conduce a que la estrategia de intervención esterilizada tenga un componente estabilizador temporal y no permanente; en el caso de México fomenta una generación de ganancias de inversionistas institucionales e internacionales.

Josefina León y César Alvarado escriben el artículo "México: estabilidad de precios y limitaciones del canal de crédito bancario", donde presentan un análisis del crédito y su influencia en el desarrollo económico de nuestro país. Los autores explican como la existencia de un oligopolio determina que en el sector financiero mexicano no fluyan los créditos a los proyectos más productivos, ni en los mejores términos, por lo que no existe seguridad de pagos y los ahorros no reciben rendimientos adecuados. Este trabajo se divide en tres partes: la primera realiza una revisión teórica de la importancia e impacto del crédito bancario; la segunda analiza el caso México, en especial las características que no permiten que el crédito bancario genere un impulso al crecimiento económico; la tercera presenta las conclusiones del artículo. Al realizar un análisis acerca del sistema bancario en México, los autores centran su desarrollo en determinar los elementos que hacen que el mercado de crédito no sea eficiente $y$, por lo tanto, no apoye en el crecimiento económico. Los elementos que marcan como determinantes para explicar esta falta de eficiencia es la existencia de una concentración tanto en la captación de depósitos como en el otorgamiento de crédito, ya que las instituciones bancarias Bancomer, Banamex y Banorte concentran $51.48 \%$ de los depósitos y 55.42\% de los créditos. Re- 
fuerzan su hipótesis de que el oligopolio es un elemento clave que no permite que el mercado de crédito sea eficiente y por lo tanto impulse el desarrollo económico del país, y es a partir de este punto que se hace la reflexión acerca de la banca de desarrollo como elemento clave para aumentar la competencia y apoyar los sectores estratégicos, que la banca comercial no ha apoyado, además de la reforma financiera que vaya en el sentido de aumentar la competencia, incrementar la inclusión financiera, el combate a la informalidad y que los intermediaros financieros corran el riesgo de los créditos otorgados.

La firma del Tratado de Libre Comercio de América del Norte (TLCAN) tenía como uno de sus múltiples objetivos la reducción del flujo de migrantes a Estados Unidos. Sin embargo, el tema migratorio no aparece formalmente en la estructura del TLCAN debido a que se pensaba que la libre movilidad de capital y de mercancías podría reducir la afluencia de migrantes. Al respecto escribe Genoveva Roldán en su trabajo titulado "Migración México-Estados Unidos: paradoja liberal renovada del TLCAN" que se compone de dos partes principales: en la primera aborda el aspecto teórico de la migración, la explicación del fenómeno y la necesidad de detenerlo a través de una integración económica; y en la segunda, se presentan las tendencias que ha tenido la movilidad laboral para los mexicanos durante los últimos 20 años. La solución a la migración, implícita en el TLCAN, era coherente con la corriente liberal y proponía la reducción del flujo de migrantes mediante la integración de los países. Esta corriente fundamenta que la apertura comercial y de inversiones promueve crecimiento económico y lleva a la convergencia económica, y así es posible reducir el flujo migratorio. Esta propuesta tiene una paradoja ya que a nivel global, en las aperturas comerciales o tratados, se hace énfasis en liberalizar el comercio, la circulación de mercancías, de capitales e inversiones, pero se ven acompañados de una contención de la movilidad laboral. En los últimos 20 años la migración entre México y Estados Unidos se ha incrementado a tal grado de ser una de las más fuertes a nivel mundial; esta realidad es incongruente con los propósitos que la firma del TLCAN debía cumplir respecto al tema migratorio.

"Comportamiento bursátil en los G-9 emergentes (BRICS+4)", de Miriam Sosa y Alejandra Cabello tiene como idea central la necesidad de buscar evidencia empírica que muestre la viabilidad del establecimiento de un grupo como el G-9 $9^{1}$ (BRICS+4), considerando la relación entre variables macroeconómicas y la actividad bursátil de cada país. Las autoras plantean que un grupo

1 Brasil, Rusia, India, China, Sudáfrica, Corea del Sur, Indonesia, Turquía y México. 
emergente económicamente significativo tiene gran alcance y posición a nivel mundial, por ello se tiene el objetivo de examinar la relación entre las variables macroeconómicas y los mercados accionarios, con la idea de evidenciar un potencial agrupamiento, si y solo si, existe homogeneidad en ciertas variables estudiadas. Las variables macroeconómicas consideradas son: el índice de precios al consumidor, la producción industrial, el volumen de exportaciones y las reservas internacionales; la variable representativa del mercado bursátil son los diferentes índices accionarios de los países en cuestión. Los modelos que se plantean son multifactoriales, VAR, descomposición de varianza y función de impulso respuesta. Considerando y refiriéndose al factor del riesgo sistemático, es decir, cómo las cuatro variables macroeconómicas afectan al sector o mercado bursátil. Los resultados del modelo multifactorial, muestran evidencia de un proceso heterogéneo, es decir, para cada una de las economías analizadas, su mercado bursátil está afectado por diferentes variables; mientras que para Brasil, Rusia o Turquía la inflación es una variable fuertemente explicativa de los índices accionarios de manera positiva; para India o China la inflación tiene un efecto negativo. Para el caso de México, la inflación y la producción industrial afectan positivamente, las reservas internacionales y las exportaciones afectan negativamente al índice accionario. Se concluye que existen diferencias marcadas en magnitud y naturaleza; es decir, un agrupamiento de países no es viable, ello por el análisis en términos de las cuatro variables macroeconómicas y su respectivo mercado bursátil, dado que son estructuras heterogéneas que presentan fuertes divergencias; aunque cabe destacar que el mercado bursátil tiene un factor común explicativo, ello hace que el sector bursátil sea sensible a estas dos variables.

El artículo "Subvenciones en la negociación del ingreso de China a la OMC: implicaciones para el desarrollo", de Monica Gambrill, menciona que hay una relación directa entre la continuación de las importaciones temporales para la exportación y el aumento en las exportaciones manufactureras de la República Popular China (RPC) después de su ingreso a la Organización Mundial de Comercio (OMC), en especial la eliminación de una serie subvenciones a la exportación y la aplicación de ciertas reglas multilaterales sobre subvenciones y concretamente, la conservación de sus zonas económicas especiales. Por lo tanto, existe un efecto positivo entre las subvenciones a la exportación con el monto de las exportaciones manufactureras y la balanza comercial. Estas acciones contradicen los postulados de la OMC, en especial, la prohibición de las subvenciones a la exportación a todo tipo de producto y a todo tipo de miembros incluidas en la Ronda Uruguay (1995) y posteriormente en el Acuerdo sobre Subvenciones y Medidas Compensatorias (ASMC) que es parte 
del Acuerdo General sobre Aranceles Aduaneros y Comercio (GATT, por sus siglas en inglés) (1994). Cabe señalar que la RPC negoció su adhesión a la OMC bajo el Acuerdo de Marrakech y el Informe del Grupo de Trabajo sobre la Adhesión de China, los cuales le concedieron ciertas excepciones en sus áreas sensibles. Lo que queda claro es que las reglas se diseñaron para satisfacer las necesidades de la RPC, privilegiando a su Inversión Extranjera Directa (IED), al mismo tiempo que obliga a la RPC a acelerar su transformación hacia una economía de mercado. De esta manera, tras el ingreso a la OMC se reportan siete ańos continuos de tasas de crecimiento extraordinariamente altas en el rubro de exportaciones, mientras que las importaciones crecieron a un ritmo menor. Esto se debe a una marcada especialización de la RPC en la exportación de bienes manufactureros y no en bienes primarios. Por último Gambrill concluye que a pesar de que el ASMC prohíbe subvenciones a la exportación, el protocolo de accesión de la RPC a la OMC ha hecho algunas excepciones a estas reglas, permitiéndole a RPC promover sus exportaciones manufactureras en sus zonas especiales que venían utilizando desde antes de su ingreso.

Germán A. de la Reza nos presenta su trabajo "Art. XXIV del GATT-OMC: la relación entre regionalismo y multilateralismo" que contempla la interacción de los Acuerdos Comerciales Regionales (ACR), así como las negociaciones multilaterales a través del Art. XXIV de la Organización Mundial de Comercio (OMC). Se menciona tres posicionamientos sobre los ACR; el primero, sobre la autonomía relativa de objetivos de los ACR, los cuales exceden su función de alternativa a las insuficiencias multilaterales; el segundo, sostiene que los ACR son un esquema intrínsecamente discriminador, y el tercero, postula que el regionalismo responde a intereses relativamente autónomos, en este sentido los ACR en sus variantes bilaterales, plurilaterales o transregionales, son copartícipes de la creación del sistema económico mundial, esta posición se convierte en la hipótesis del autor. Desde una visión histórica, los ACR no han tenido efectos positivos, incluso en la actualidad existen testimonios como la Cuarta Conferencia Ministerial, Doha 2001, que testimonia la incompatibilidad de los acuerdos, a pesar de la entrada de China a la OMc. A pesar de una virtual parálisis de los objetivos de la OMC, entre 2009 y 2014, los ACR continúan invocando la conjetura del regionalismo como alternativa a los problemas de la omc. Sin embargo, la capacidad disminuida del Art. XXIV en los procesos de negociación, no han impulsado una mayor profundización y coherencia entre el regionalismo y el multilateralismo.

La sección de reseñas recomienda cinco libros: La economía solidaria en México de Boris Marañón (coord.), escrita por Hilda Caballero; Economía de las asociaciones público-privadas. Una guía básica de Eduardo Engel y otros 
Editorial

autores, reseñado por Daniel Flores; La economía petrolera en un mercado politizado y global. México y Colombia de la autora Alicia Puyana, escrita por Isabel Rodríguez; Trilogía Cómo sembrar el desarrollo en América Latina, Colección de Libros Problemas del Desarrollo de Alicia Girón (coord.), escrita por Nora Ampudia. Finalmente, Erika Martínez promueve el libro Buen vivir y descolonialidad: crítica al desarrollo y la racionalidad instrumentales de Boris Marañón.

Alicia Girón

La Dirección de la Revista Ciudad Universitaria, marzo 2015 